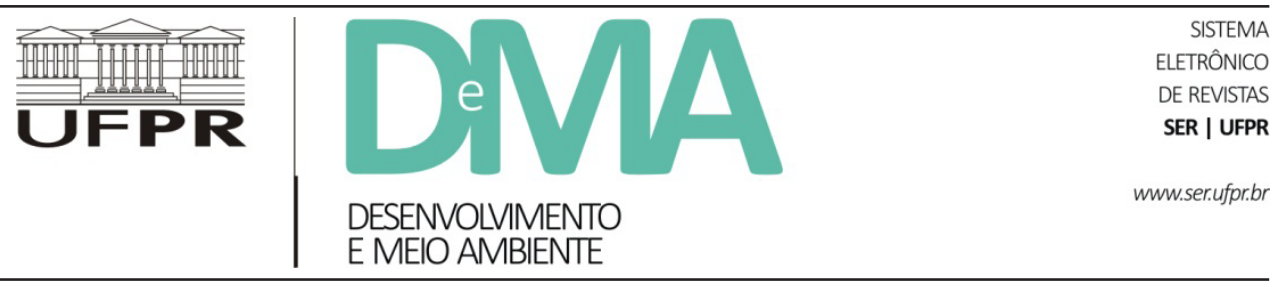

\title{
Mudanças tecnológicas em campo: do surgimento de um novo código sociotécnico à concepção de processos desviantes de desenvolvimento rural
}

\section{Technological Changes at Field: from the Emergence of a New Socio-Technical Code to the Conception of Deviant Processes of Rural Development}

\author{
Monique MEDEIROS ${ }^{1 *}$, Ademir Antonio CAZELLA ${ }^{1}$ \\ ${ }^{1}$ Programa de Pós-Graduação em Agroecossistemas, Universidade Federal de Santa Catarina (UFSC), Florianópolis, SC, Brasil. \\ *E-mail de contato: mmedeiros@ymail.com
}

Artigo recebido em 10 de novembro de 2015, versão final aceita em 3 de agosto de 2016.

RESUMO: Direcionados por preocupações acerca das consequências negativas de determinadas transformações tecnológicas no campo e conscientes da complexidade da mudança desse cenário, atores sociais articulam-se na busca pela superação das adversidades resultantes da modernização. Neste contexto, mudanças e inovações estão ocorrendo constantemente. Considerando que essa diversidade de trajetórias desviantes necessita ser estudada, este artigo analisa o processo de construção social de um novo código sociotécnico que vem desencadeando dinâmicas de desenvolvimento rural adequadas às especificidades socioeconômicas, ambientais e culturais do Litoral Norte do estado brasileiro do Rio Grande do Sul. Alicerçada em dados construídos por meio de entrevistas abertas e semiestruturadas e pesquisas documentais, a análise enfatiza a articulação de agricultores familiares, mediadores sociais e pesquisadores na consolidação deste código sociotécnico inovador, que ressignifica antigos costumes e tradições dos processos agrícolas. À luz da Teoria da Construção Social da Tecnologia e da Perspectiva Orientada ao Ator, evidencia-se que tal inovação, ainda que apresente limitações, desencadeia estratégias criativas de produção de conhecimentos na operacionalização de novas conexões entre o desenvolvimento de tecnologias e o contexto social ao qual estão imbricados os atores.

Palavras-chave: atores sociais; novo código sociotécnico; desenvolvimento rural; litoral norte do Rio Grande do Sul.

ABSTRACT: Driven by concerns about the negative consequences of certain technological changes in the field and aware of the complexity of it in this scenario, social actors articulate themselves in the search for overcoming the adversities resulted from modernization. In this context, change and innovation are occurring constantly. Considering that this diversity of deviant trajectories needs to be studied, this article analyzes the social construction process of a new socio-technical code that is triggering rural development dynamics appropriate 
to the socioeconomic, environmental and cultural specificities of the north coast of the Brazilian state of Rio Grande do Sul. Grounded in data analyzes built through open and semi-structured interviews and documentary research, the analysis emphasizes the articulation between family farmers, social mediators and researchers in the consolidation of this innovative socio-technical code, that gives a new meaning to ancient customs and traditions of agricultural processes. Guided by Theory of Social Construction Technology and by Actor Oriented Perspective, it reveals that innovation, although present limitations, results in creative strategies of knowledge production in the operationalization of new connections between the development of technologies and the social context to which the actors are intertwined.

Keywords: social actors; new socio-technical code; rural development; north coast of Rio Grande do Sul.

\section{Introdução}

A estandardização da ciência e da tecnologia fez com que a agricultura fosse sendo desconectada dos contextos sociais e ecológicos, da conformação de tempo e espaço e da elaboração de produtos de qualidades locais específicas, bem como da família como princípio de organização social. Esses processos têm irradiado efeitos tanto no modo de compreender a agricultura quanto na forma de realizar suas práticas características (Ploeg, 1994).

Todavia, ainda que essa desconexão da agricultura como prática sociocultural tenha predominado na sociedade, nem todos os grupos sociais permaneceram acríticos a esse processo e às suas consequências. Muitos agricultores resistiram de distintas maneiras. Ao invés de vivenciarem como uma desintegração dos seus mundos de vida, eles transformaram o novo código de comunicação e racionalidade que lhes estava sendo posto. Conforme suas necessidades e interesses, inter-relacionaram materialidades associadas à modernidade e à tradição (Arce \& Long, 2000).

No Litoral Norte do Rio Grande do Sul, por exemplo, um conjunto de agricultores, aliados a pesquisadores, extensionistas rurais e consumidores, empreende iniciativas que implicam em reavaliações e reinvenções não somente de formas de produção agrícola, como também de novos projetos de desenvolvimento rural. Opondo-se à padronização modernizante, que visa encaixar as práticas agrícolas nos pacotes tecnológicos, esses atores sociais vêm construindo iniciativas inovadoras que destacam a importância da tecnologia ser desconstruída para poder ser combinada seletivamente com os elementos locais que caracterizam cada modo de praticar agricultura (Long \& Ploeg, 1994). Nesses processos, é possível verificar o papel preponderante da família como estrutura fundamental de organização da reprodução social por meio da formulação de estratégias que remetem diretamente à transmissão do patrimônio material e cultural e à transmissão da unidade agrícola (Carneiro, 1999).

No local de estudo, a exemplo do que ocorreu na maior parte da região Sul do país, a modernização do campo materializou-se por meio da difusão de pacotes tecnológicos, o que induziu os agricultores à adoção de cultivos específicos, até então inexistentes na região, como o de tabaco (Cotrim et al., 2007). O cultivo de tabaco de forma integrada às indústrias fumageiras remonta à década de 1950 , mas nos anos 1960essa espécie foi difundida entre os agricultores como a principal alternativa para modernizar a agricultura da região.

Os sistemas de produção baseados na cadeia produtiva ligada à produção de fumo passaram a ser adotados por uma razoável quantidade de agricultores locais (ANAMA/PGDR, 2000; Gerhardt, 
2002). Em paralelo, o uso de insumos e agroquímicos difundiu-se, em grande parte por incentivo do governo estadual, o qual implantou na região um centro da Fundação Estadual de Pesquisa Agropecuária e escritórios da Associação Rio-grandense de Empreendimentos de Assistência Técnica e Extensão Rural/Associação Sulina de Crédito e Assistência Rural (EMATER/ASCAR - RS) (Medaglia, 2010).

Os efeitos desse processo marcam a realidade atual da agricultura do Litoral Norte Gaúcho. Uma forte especialização da agricultura está presente nas áreas de várzeas dos vales e nas planícies, praticada por agricultores com maior disponibilidade de áreas planas, que detêm uma melhor situação econômica. Como uma reduzida parcela de agricultores possui áreas planas em maior quantidade, a maioria dos agricultores continua a cultivar nas encostas sem o uso intensivo de tecnologias modernas, mas com rendimentos inferiores, comparados às áreas de várzea (Cotrim et al., 2007).

Além dos desafios gerados pelos processos modernizantes, novos obstáculos tiveram que ser transpostos para a manutenção de uma parcela significativa de agricultores familiares da região. Como parte considerável da paisagem local é constituída por remanescentes de florestas de Mata Atlântica, a partir do início da década de 1990a fiscalização ambiental por parte do poder público passou a ser intensificada e as restrições legais de uso do solo e da vegetação geraram dificuldades, principalmente, para os agricultores das áreas de encostas.
Entretanto, os agricultores familiares que ali permaneceram iniciaram estratégias de adaptações e rearranjos em relações sociais e de trabalho e de reinvenções de tecnologias. Como resultado desse conjunto de estratégias colocadas em prática por meio de experimentações, a região é caracterizada hoje por um mosaico cultural e produtivo. Nesse mosaico, observa-se o prevalecimento de uma agricultura familiar voltada à produção de alimentos em sistemas diversificados, com destaque para os cultivos de base ecológica ${ }^{1}$, os quais vêm sendo edificados pela consolidação de um código sociotécnico específico. Esse código se refere a um conjunto de acordos tácitos estabelecidos pelos atores sociais que compartilham uma concepção de desenvolvimento desviante da convencional. Disso resulta uma classificação de práticas sociais e técnicas como permitidas ou proibidas, de acordo com sua associação a significados ou propósitos (Feenberg, 2002).

Este artigo inscreve-se no desafio de analisar esse processo de construção social de um novo código sociotécnico que vem desencadeando dinâmicas inovadoras e complexas de desenvolvimento rural adequadas às especificidades socioeconômicas, ambientais e culturais do Litoral Norte gaúcho, mais especificamente dos municípios de Três Forquilhas, Terra de Areia, Itati, Osório, Maquiné e Dom Pedro de Alcântara (Figura 1), nos quais as mudanças são mais evidentes.

Do ponto de vista metodológico,o estudo está baseado em informações obtidas por meio de entrevistas abertas e semiestruturadas, direcionadas

\footnotetext{
${ }^{1}$ Modelo de agricultura que desvia e contraria o modelo de agricultura convencional, a qual faz uso de agroquímicos e que, reconhecidamente, é dependente de recursos naturais não renováveis e, portanto, incapaz de perdurar no tempo. As práticas da agricultura de base ecológica têm como foco o equilíbrio entre os diversos fatores presentes no trabalho com a agricultura, os quais se referem desde o respeito com suas criações animais e preocupação em não gerar desperdícios, reaproveitando ao máximo o material que sobra de suas atividades, até sua participação em relações coletivas, buscando uma melhor qualidade de vida para os dias atuais e para os dias futuros (Caporal \& Costabeber, 2004).
} 


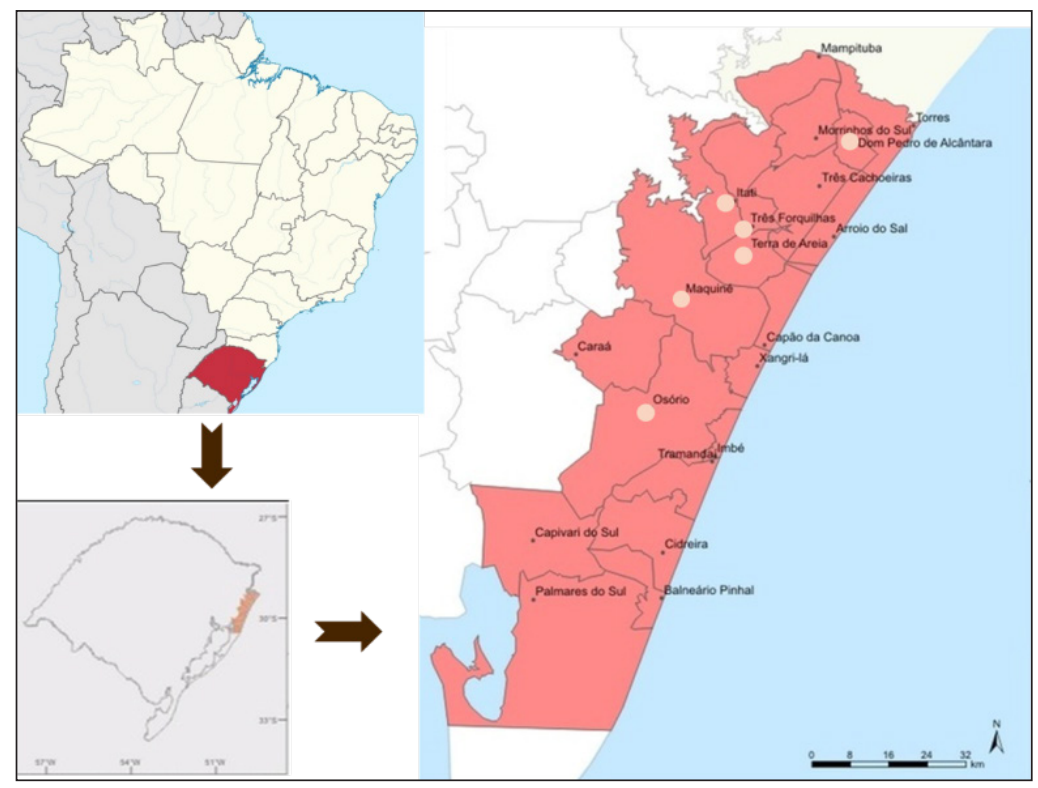

FIGURA 1 - Localização da região do Litoral Norte do Rio Grande do Sul, com destaque para os municípios de origem dos agricultores familiares envolvidos na pesquisa.

FONTE: adaptada do site<http://www1.seplag.rs.gov.br/atlas>. Acesso em: 12 fev. 2014.

a mediadores sociais e agricultores familiares atuantes no recorte empírico,e pesquisa documental ${ }^{2}$ (Godoi \& Mattos, 2006).Além desta introdução, quatro partes compõem a estrutura principal do artigo. A primeira relaciona a perspectiva elaborada por Trevor Pinch \& Wiebe Bijker (1987), denominada Construção Social da Tecnologia, com a Perspectiva Orientada ao Ator (POA), formulada pelos antropólogos Norman Long e Alberto Arce e pelo sociólogo Jan Douwe van der Ploeg, pesquisadores da Universidade de Wageningen, na Holanda. $\mathrm{O}$ intuito dessa articulação teórica é evidenciar o desencadeamento de mudanças sociotécnicas na agricultura que se constituem e se fortalecem de forma contra-hegemônica ao modelo convencional de modernização agropecuária.

A segunda parte destaca as especificidades da região e apresenta as iniciativas que estão sendo postas em marcha por um conjunto de atores sociais, que vêm suscitando processos de desenvolvimento rural desviantes dos ideais do marco tecnológico dominante. A terceira enfatiza a importância da conexão entre esses atores sociais e do respaldo de duas políticas públicas de compra de alimentos na fundamentação de tais processos. A quarta e última parte apresenta as considerações finais,

\footnotetext{
${ }^{2}$ Foi possível acompanhar treze mediadores sociais e cinquenta famílias de agricultores em atividades cotidianas, como o trabalho nas feiras livres, nos encontros e reuniões, nas atividades nas lavouras e em sua relação com pesquisadores e gestores públicos atuantes na região. Tais atividades foram desenvolvidas pela primeira autora, entre agosto de 2011 e agosto de 2013, na condição de extensionista rural da EMATER do Rio Grande do Sul e, entre setembro de 2013 e junho de 2016, como doutoranda do Programa de Pós-Graduação em Agroecossistemas da Universidade Federal de Santa Catarina.
} 
dando ênfase às potencialidades dessas iniciativas, bem como indicando algumas de suas limitações, em especial no que se refere à abrangência desses processos e às consequências desencadeadas pelo marco tecnológico dominante.

\section{Atores sociais e a reconfiguração da tecnologia: o cruzamento de fronteiras teóricas}

As tecnologias desempenham um papel central nos processos de mudança social:demarcam posições e condutas da sociedade; condicionam estruturas de distribuição social, custos de produção e acesso a bens e serviços; geram problemas sociais e ambientais e facilitam ou dificultam sua resolução (Thomas, 2009). Entretanto, muitas de suas faces são desconhecidas. Apenas recentemente vem se destacando a ideia de que, para além de produtos ou processos produtivos, a dimensão tecnológica compreende distintas formas de organização social. Essas formas podem incluir desde aquelas que atribuem uma ordem a um conjunto de operações de produção até aquelas que adquirem formatos normativos, como os sistemas legais ou as regulações de comércio. Neste nível organizacional, uma legislação não se diferencia de outros artefatos tecnológicos (Thomaset al., 2008).

As multifacetas da tecnologia foram embasadas e aprofundadas por um conjunto de estudos, principalmente oriundos da sociologia e da filosofia, que procuraram investigar e compreender melhor a co-construção da tecnologia e da sociedade. Dentre as abordagens neste campo surgiu, nos anos 1980, a Construção Social da Tecnologia (CST), uma perspectiva que assume que a mudança tecnológica se encontra determinada por processos sociais mais do que por qualquer lógica tecnológica interna. Esses autores argumentam que os critérios da funcionalidade tecnológica possuem uma origem social. Desse modo, colocam em questionamento as explicações do êxito dos artefatos técnicos, ou seja, aquelas que afirmam, de forma ingênua, que o critério de escolha pela adoção de novos artefatos técnicos se deve exclusivamente a um melhor desempenho funcional.

Segundo Thomas (2009), a abordagem da CST possibilita colocar em evidência a existência de estilos sociotécnicos de transição tecnológica e processos de inovação particulares. Para além da confluência de explicações sobre a singularidade dos processos sociotécnicos locais, a abordagem aporta novos elementos de análise. Dentre esses elementos, destacam-se o uso intensivo de operações de ressignificação de tecnologias, a operacionalização de conhecimentos genéricos, a reutilização de habilidades, o estabelecimento de relações específicas entre usuário/produtor/provedor, o desenvolvimento de dinâmicas de melhoria de problemas e a geração de soluções não estandardizadas.

Corroborando a reflexão acerca de que a CST, para além de uma crítica às explicações comuns sobre o êxito de algumas tecnologias, constitui-se como uma teoria da mudança tecnológica posta em marcha por distintos grupos sociais (Bruun \& Hukkinen, 2008), considera-se profícua a sua articulação com uma análise orientada a microprocessos individuais e coletivos. Dessa forma, propõe-se sua aproximação à Perspectiva Orientada ao Ator, uma abordagem analítica originada da sociologia do desenvolvimento e fundamentada em estudos interacionistas e fenomenológicos realizados nos anos de 1960. Essa perspectiva defende que, mesmo em circunstâncias estruturais similares, diferentes formas sociotécnicas são desenvolvidas devido aos variados modos com os quais os atores encaram seus problemas cotidianos, organizacionais ou cognitivos (Long, 2007). 
A complementaridade dessas perspectivas assenta-se, em especial, no fato de a Construção Social da Tecnologia evidenciar esses microprocessos que estão articulados com as constituições de problemas pela sociedade e as escolhas tecnológicas para a mudança e a melhoria de situações problemáticas. Segundo Pinch \& Bijker (2008), a construção de novos códigos sociotécnicos está diretamente relacionada à constituição de problemas pela sociedade, visto que um problema é definido como tal somente quando há um grupo social relevante para o qual um fato se constitui um problema. Nessa acepção, são compreendidas como grupos sociais relevantes as instituições ou organizações cujos membros compartilhem o mesmo conjunto de significados vinculados a um artefato específico.

A proximidade entre o conceito de grupo social relevante e a noção de agência, um dos pilares centrais da POA, sobressai na compreensão de que para a constituição de um grupo social relevante é preciso que os indivíduos, além de partilharem percepções acerca dos problemas que os rodeiam, busquem coletivamente caminhos que os levem às melhorias desejadas (Pinch\& Bijker, 2008). De acordo com Long \& Ploeg (1994), o enfrentamento das situações problemas é possibilitado pela mobilização da agência dos atores que constituem esses grupos sociais. Para Giddens (1984), a agência não se refere somente às intenções que as pessoas têm para realizar determinadas coisas, mas, sobretudo, à sua capacidade de colocar essas coisas em prática. A agência depende da habilidade do indivíduo de gerar mudanças em relação a um estado de coisas ou curso de eventos preexistentes, o que implica que todos os agentes, mesmo aqueles que se encontram em posições de subordinação, se apropriam de um determinado tipo de poder e podem exercer influências. Em termos gerais, a noção de agência atribui ao ator, individual ou grupo social, a habilidade de traçar caminhos alternativos para o enfrentamento das situações problemáticas que estão sob diversificadas formas de coerção (Long \& Ploeg, 1994).

Essa habilidade, que requer organização, se traduz na capacidade de influenciar na interpretação que os atores sociais constroem coletivamente dos artefatos e, consequentemente, nas escolhas tecnológicas que norteiam os caminhos a serem trilhados (Pinch \& Bijker, 2008). Segundo as concepções da Construção Social da Tecnologia, os artefatos podem ser interpretados pelos atores de maneiras muito diferentes, visto que possuem flexibilidade interpretativa. Essa interpretação depende tanto da constituição físico-estrutural dessas tecnologias quanto do tipo de problemas para os quais uma ou mais tecnologias são consideradas uma solução.

Diferentes grupos de pessoas definem potencialidades e limitações das características das tecnologias, bem como a relevância dos problemas que possam ser melhorados com o uso dessas tecnologias de formas distintas (Bijker, 1995).As diferenças tornam-se particularmente visíveis na ocorrência de controvérsias tecnológicas (Bruun $\&$ Hukkinen, 2008). Ainda que, por vezes, as trajetórias diferentes sejam alinhadas e sigam por direções similares, criando estabilidade e resiliência, em outras as trajetórias podem divergir e resultar em desajustes e tensões. Afinal, o surgimento da agência é desencadeado pelas interações, interfaces e transformações entre as visões de mundo, os interesses e os repertórios culturais dos atores nos grupos sociais (Long, 2001).

Nos campos de disputa que se delineiam, ganham importância as diferenças de poder e os distintos tipos de capital, ou seja, vantagens socioeconômicas e culturais,mobilizados pelos atores e os grupos sociais que constituem (Bourdieu, 1989). Quando as atividades desses grupos e suas trajetórias seguem para diferentes direções, ocor- 
rem desalinhamentos e instabilidades nos marcos tecnológicos (Geels, 2004). Para Bijker (1995, p. 276), o termo "marco tecnológico" (technological frame) descreve como os grupos sociais relevantes interpretam o artefato em si. De acordo com esse autor, por marco tecnológico pode-se entender um conjunto de elementos sociais que direciona as interações que ocorrem dentro dos grupos sociais e os conduzem à atribuição de sentido aos artefatos técnicos. Esses elementos são, por exemplo, objetivos, percepção de problemas, estratégia de melhoria de problemas, requerimentos que devem ser cumpridos, teorias habituais, conhecimento tácito e métodos e técnicas de planejamento.

Alguns atores têm uma alta inclusão no marco tecnológico ao qual pertencem, estando alinhados com o conjunto de valores e objetivos desta estrutura e ocupando posição central nas decisões, enquanto outros não possuem um vínculo tão forte com a estrutura na qual estão inseridos, ocupando posição marginal. Apesar dessas diferenciações, a inclusão em um dado marco tecnológico não é algo a ser visto de forma binária. Em vez de ser central ou marginal, um membro de um grupo social pode ter distintos graus de inclusão no marco tecnológico e essas graduações variam de acordo com as situações sociais nas quais se está envolvido (Bijker, 1995).

A compreensão acerca dos gradientes de inclusão dos atores sociais nos marcos tecnológicos pode ser aprofundada pela incorporação da noção de arena social- tributária à POA -à análise de construção desses marcos. A maior ou menor inclusão dos indivíduos em um marco tecnológico está vinculada às relações de poder que se dão nas arenas sociais que o delineiam. Nessas situações sociais, denominadas arenas, os atores confrontam interesses, mobilizam as relações sociais e utilizam discursos com a finalidade de justificar objetivos específicos (Long, 2001).
As opiniões inicialmente apresentadas nas arenas sociais vão sendo reavaliadas e negociadas pelos grupos até que tendam a uma estabilização. Posterior a este estágio de convergência de opiniões, o processo de construção do artefato começa a caminhar para um fechamento da situação de conflito (Fertrin, 2008). Conforme Pinch \& Bijker (1987), podem existir dois mecanismos de fechamento diferentes para a situação: o fechamento por redefinição do problema e a retórica do fechamento.

$\mathrm{O}$ primeiro tipo apresentado pelos autores, como a própria denominação sugere, ocorre quando há o surgimento de novas concepções acerca do problema anteriormente diagnosticado, o que conduz à sua redefinição. $\mathrm{O}$ segundo mecanismo acontece com a estabilização do artefato e a melhoria do problema construído. A ocorrência desse segundo mecanismo não indica que a controvérsia tecnológica tenha sido resolvida plenamente. Entretanto, as futuras inovações que podem emergir, ainda visando à melhoria desse problema, tendem a se desenvolver a partir do modelo já conhecido, distanciando-se cada vez mais de uma possibilidade de mudança radical.

Bijker (1995) argumenta que a natureza da mudança tecnológica depende das configurações dos marcos tecnológicos em torno do artefato. Sua hipótese é a de que o caráter da mudança está diretamente relacionado ao fato de a configuração sociotécnica envolver somente um ou vários marcos tecnológicos ou, ainda, de não existir esse marco. Se não há um marco tecnológico dominante na construção de um novo artefato, se supõe que os atores identificaram problemas e sugeriram soluções inovadoras.

Assim, existiria uma probabilidade relativamente mais alta de aparição de inovações por fora dos marcos tecnológicos hegemônicos. Se existir um marco tecnológico claramente dominante, as 
inovações tenderão a ser mais convencionais, seguindo o padrão de pensamento vigente. Por conseguinte, os estímulos para as mudanças sociotécnicas mais radicais surgirão de atores sociais com baixa inclusão no marco tecnológico dominante.

As reflexões suscitadas pela articulação da Perspectiva Orientada ao Ator à Abordagem da Construção Social da Tecnologia propiciam um aprofundamento na análise acerca de processos de transformações sociotécnicas que estão em curso no espaço rural. A POA possibilita a distinção de novas dinâmicas de desenvolvimento ruralcolocadas em marcha por distintos atores sociais, que surgem como alternativas ao modelo hegemônico pautado na Revolução Verde (Long, 2007; Ploeg et al., 2004). Por sua vez, a Construção Social da Tecnologia permite identificar a emergência da construção sociotécnica de sistemas de produção e organização que desviam do marco tecnológico dominante da agricultura moderna, balizando essas novas dinâmicas de desenvolvimento (Bijker, 1995).

A concatenação dessas duas concepções favorece a percepção de que a articulação dos diversos grupos sociais relevantes, compostos por variados atores sociais, é um catalisador da definição e da operacionalização de seus objetivos e práticas de gerenciamento, relacionados à outra forma de conceber a agricultura e o espaço rural, com base em diferentes critérios, experiências e perspectivas. Considerando seus interesses, os grupos sociais, ao invés de reorganizarem sua prática agrícola de forma a atender os padrões de novas tecnologias determinadas pelo marco tecnológico dominante, desconstroem e reconstroem tais tecnologias para que possam ser combinadas seletivamente com outros elementos locais (Long \& Ploeg, 1994).

Dessa forma, são construídas iniciativas inovadoras constituintesde um novo código sociotécnico. Esse código desvia das concepções de desenvol- vimento pactuadas hegemonicamente, ao passo que é guiado pelo compartilhamento de marcos tecnológicos.Ou seja, pelas combinações de valores culturais, objetivos socioambientais, econômicos e tecnológicos, como ocorre no recorte empírico analisado.

\section{Lançando o olhar para o contexto empírico}

A região do Litoral Norte do Estado do Rio Grande do Sul é composta por 20 municípios, os quais totalizam uma área de $5.132,8 \mathrm{~km}^{2} \mathrm{e}$ população de 297.009 habitantes (IBGE, 2010). A população atual é resultante, inicialmente, do povoamento indígena, das colonizações açoriana, portuguesa e africana ocorridas no século XVIII e, posteriormente, no século XIX, das colonizações alemã, italiana, polonesa e japonesa (Cotrim et al., 2007).

Os primeiros habitantes da região, ainda que os recortes espacial e temporal de ocupação dessas populações sejam pouco precisos, foram identificados como sendo da grande nação Guarani. A sobrevivência dessa nação baseava-se em uma agricultura que consistia no corte da vegetação das pequenas áreas destinadas ao cultivo para o autoconsumo, a posterior queimada e a realização do plantio sobre as cinzas e fragmentos da floresta. Quando a terra atingia seu esgotamento de fertilidade ou quando era dominada por plantas espontâneas identificadas como desprovidas de valor nutricional pela população, a área de cultivo era então abandonada e uma nova parcela seria preparada para ser cultivada. Os costumes indígenas deixaram como herança nessa região, além de hábitos diários e palavras específicas, os cultivos de milho, abóbora, batata-doce, mandioca, feijão e amendoim (Pettenon, 2014). 
Os processos de colonização sucedidos no Litoral Norte Gaúcho ao longo dos últimos três séculos instituíram uma transformação abrupta nos modos de vida para as populações indígenas que ali se encontravam. Apesar de existirem remanescentes destes povos na região, pode-se observar que suas lógicas de trabalho e muitos de seus costumes foram suprimidos e desestruturados para que novas populações e técnicas de sobrevivência no território fossem sobrepostas às suas (ANAMA/ PGDR, 2000).

No que se refere aos sistemas produtivos, durante aproximadamente 100 anos, estes acabaram sendo restritos principalmente à criação de gado, à produção de cana-de-açúcar e à agricultura açoriana baseada na venda de excedentes. No século XVIII, concomitante ao início da chegada dos colonizadores europeus à região, vieram também escravos africanos, inicialmente trazidos para trabalhar nas lavouras de cana-de-açúcar. Assim como ocorre com as populações indígenas, ainda hoje a região conta com núcleos populacionais negros remanescentes de africanos (ANAMA/PGDR, 2000).

Em meados do século XIX, usufruindo das diferenças de relevo e do microclima, os colonos realizavam na meia encosta dos morros do Litoral Norte Gaúcho uma agricultura que mesclava técnicas tradicionais indígenas e africanas com seus conhecimentos europeus. Mais fortemente entre os anos 1960 e 1990, as dificuldades econômicas decorrentes das limitações de produção impostas pelas peculiaridades topográficas da região e as consequências socioambientais negativas da agricultura intensiva, em especial voltada ao cultivo de tabaco, fizeram com que os agricultores repensassem suas estratégias de reprodução socioeconômica.

Com o decorrer do tempo, o cultivo de tabaco apresentou distintas limitações, dentre elas a exigência de cultivo em planícies, as condições penosas de trabalho, assim como o aumento das concentrações de metais pesados e sedimentos no solo e a poluição das águas pelo uso intensivo de agrotóxicos. Esse conjunto de fatores explica o fato de, já no final da década de 1970, muitos agricultores abandonarem o sistema integrado com as indústrias fumageiras (Gerhardt, 2002). Dentre estes, alguns começaram a instalar em suas unidades agrícolas sistemas produtivos que viriam a ser os principais cultivos comerciais encontrados nos municípios do Litoral Norte: a horticultura, a rizicultura e a fruticultura, mais especificamente a produção da banana tipo prata (ANAMA/PGDR, 2000).

Se, por um lado, essa realidade levou boa parte da população local de agricultores familiares a abandonar o campo em busca de novas oportunidades de trabalho na cidade, por outro lado, muitos dos agricultores que permaneceram na região encontraram na figura de comerciantes intermediários um meio para garantir sua continuidade no espaço rural.Principalmente frente às dificuldades de acesso aos mercados, bem como à dependência desses intermediários que transportavam sua produção até os pontos de comercialização e retinham a maior parte do lucro adquirido nas vendas, um coletivo de 27 agricultores familiares de três municípios da região iniciou um processo de organização produtiva.

Dessa forma, em setembro de 2006, tem origem a Cooperativa Mista de Agricultores Familiares de Itati, Terra de Areia e Três Forquilhas (COOMAFITT). Esta organização surge então como estratégia de criação de novos espaços de troca de informações, bem como para buscar diferentes mercados de comercialização para os produtos das unidades agrícolas familiares. Desde sua formação, esse grupo vem se fortalecendo e se expandindo e, atualmente, 173 agricultores dos municípios de abrangência da Cooperativa compõem seu quadro social. 
Esse progresso foi resultante, em especial, da integração da Cooperativa, entre 2008 e 2010, a duas políticas públicas de apoio aos chamados mercados institucionais. Uma dessas políticas se refere ao Programa de Aquisição de Alimentos (PAA). Regulamentada em 2008, tem como principais finalidades a promoção do acesso à alimentação e o incentivo à agricultura familiar. Por meio do PAA, os alimentos adquiridos dos agricultores familiares são destinados às pessoas em situação de insegurança alimentar e nutricional, àqueles atendidos pela rede assistencial e às organizações de alimentação e nutrição (MDS, 2015). A outra política alude ao Programa Nacional da Alimentação Escolar (PNAE), a qual possibilita a oferta de alimentos adquiridos da agricultura familiar aos alunos de escolas públicas de educação básica do Brasil (FNDE, 2011) ${ }^{3}$. Esses canais de comercialização, mormente o PNAE, se constituíram nos mercados mais importantes para a produção das famílias cooperadas.

O apoio inicial da mediação social desempenhada por um coletivo de técnicos dos escritórios municipais da EMATER localizados na região também foi significativo para o robustecimento da organização. Tais mediadores sociais, indivíduos dotados de posição e função, segundo atribuições definidas em específicos campos de significação, intervieram na transformação da vida social local, inclusive na expansão da rede de relações sociais na região (Long, 2007). A troca de informações técnicas e administrativas e a construção de laços de confiança entre agricultores e mediadores sociais fizeram com que os representantes da COOMAFITT compreendessem a importância de se conectarem a outras organizações da agricultura familiar.

Assim, essa organização estabeleceu vínculos com a Cooperativa de Consumo e Comercialização dos Pequenos Produtores Rurais do Litoral Norte (COOPVIVA). Sediado em Osório, esse outro grupo social constituído por agricultores familiares também é diretamente assessorado pelos extensionistas dos escritórios da EMATER alocados nos municípios vizinhos. Para além do município sede, a Cooperativa abrange os municípios de Maquiné, Caraá, Rolante, Santo Antônio da Patrulha e Terra de Areia.

A aproximação, que partiu do interesse em viabilizar aspectos logísticos, como a entrega compartilhada de alguns produtos, acabou resultando em uma maior afinidade entre essas organizações. As consequências positivas dessas experiências coletivas incentivaram ambas as cooperativas a se inter-relacionarem com novos atores sociais. Dessa forma, estabeleceram parcerias também com as ONGs Associação Nascente Maquiné (ANAMA) ${ }^{4}$ e Centro Ecológico 5 .

\footnotetext{
${ }^{3}$ Apesar de ter sido criado como Programa Nacional de Alimentação Escolar em 1979, foi a partir de 2009 que mudanças significativas no programa garantiram que, no mínimo, $30 \%$ dos repasses do Fundo Nacional de Desenvolvimento da Educação fossem investidos na aquisição de produtos da agricultura familiar da região, priorizando assentamentos de reforma agrária, comunidades tradicionais, indígenas e comunidades quilombolas (FNDE, 2011).

${ }^{4}$ Fundada em 1997, a ANAMA concentra seus trabalhos de pesquisa e de extensão rural no município de Maquiné e seu entorno. A ONG busca realizar a mediação entre a realidade local e outras instâncias institucionais ligadas à pesquisa, à extensão, à ação comunitária, aos movimentos sociais organizados e à formulação de políticas públicas, tendo como linha condutora a questão ambiental aliada à valorização da diversidade cultural. Para tanto, conta com a parceria de diferentes grupos e instituições locais e com o financiamento, principalmente, do Governo Federal (ANAMA, 2015).

${ }^{5}$ Criada em 1985, no município de Ipê, região Serrana do Rio Grande do Sul, a ONG surge com o intuito de desenvolver a agricultura ecológica por meio de projetos e de assistência técnica junto às famílias de agricultores ecologistas.Atualmente, desenvolve projetos financiados pelo Governo Federal e por instituições internacionais, como o KFW, banco alemão de desenvolvimento, em duas regiões distintas do Rio Grande do Sul: a Serra e o Litoral Norte (Centro Ecológico, 2010).
} 
Embora essas distintas parcerias sejam importantes para o desenvolvimento de ambas as cooperativas, as interações entre a EMATER e as ONGs locais apresentam limitações, especialmente no que se refere à operacionalização das iniciativas no campo. Enquanto a instituição EMATER aponta que as ONGs não têm uma continuidade de suas ações devido ao fato de os recursos financeiros com as quais trabalham serem provenientes de projetos de curta duração, as ONGs afirmam que determinados técnicos da EMATER ainda apresentam resistência para o trabalho em parceria.

As visões divergentes que esses grupos possuíam da agricultura durante o auge do período da Revolução Verde são uma pista interessante para o entendimento de alguns desacordos atuais. De um lado, a EMATER surge no Rio Grande do Sul em 1955, e mais especificamente no Litoral Norte em meados da década de 1970, para operacionalizar a difusão dos pacotes tecnológicos entre os agricultores, fortemente incentivada pelo Estado. Enquanto que, do outro lado, as ONGs surgem anos mais tarde, entre as décadas de 1980 e 1990, movidas pelo intuito de contestar as opções tecnológicas difundidas, apontando as consequências desses processos, além de propor alternativas a essas perspectivas de produção para os agricultores, em especial os familiares.

Entretanto, de forma mais veemente em meados da década de 2000, os direcionamentos da EMATER passaram a ser avaliados, revistos e então reconstruídos. A organização de assistência técnica e extensão rural gaúcha passou, gradativamente, a considerar como essencial a construção de estratégias de desenvolvimento que abarcassem, para além das questões econômicas, as dimensões ambientais e socioculturais.

A pesquisa de campo e a experiência de trabalho na EMATER revelaram que, apesar das transformações na visão de trabalho dessa organização, nem todo o seu corpo técnico as incorporou em suas atividades. Mesmo que essas modificações tenham feito com que o público prioritário da instituição passasse a ser justamente composto por aqueles agricultores que mais haviam sido prejudicados com os resultados da modernização da agricultura, a ideologia produtivista que pautou durante longos anos as ações da EMATER ainda se encontra arraigada no direcionamento dado às atividades de assistência técnica e extensão rural por alguns escritórios municipais.

Atualmente, a ratificação da necessidade de existência dessa organização, bem como dessas ONGs, tem como base estrutural o atendimento aos agricultores familiares, remanescentes de quilombos, pescadores artesanais, indígenas e agricultores assentados pela reforma agrária. Tendo em vista que as ações tanto da EMATER quanto das ONGs são, em grande parte, financiadas com recursos públicos, muitas vezes estas concorrem por recursos em determinadas chamadas públicas ${ }^{6}$, o que tem se mostrado, atualmente, motivo de disputas acirradas. Todavia, a chegada de novos extensionistas nos escritórios municipais da EMATER do Litoral Norte e nas ONGs vem estimulando novas tentativas de aproximação entre esses atores sociais na

\footnotetext{
${ }^{6}$ Dispositivos utilizados pelo Estado para formalização de inexigibilidade de licitação. Neste caso, são elaboradas para a contratação de serviços de Assistência Técnica e Extensão Rural, previstos como serviços de educação não formal de caráter contínuo, a serem desenvolvidos no meio rural, com vistas à promoção e à divulgação de conhecimentos para gestão, produção, beneficiamento e comercialização de atividades e práticas agropecuárias, agroextrativistas, florestais, artesanais, dentre outras. Vale mencionar que esses mesmo dispositivos também são operacionalizados na compra de merenda escolar realizada por meio do PNAE (Nicolino, 2014).
} 
esfera local. Os novos olhares desses profissionais, muitas vezes com formações interdisciplinares, têm se mostrado cruciais nesse aspecto.

A renovação de ideias e de esforços tem sido prolífica e vem desencadeando trabalhos conjuntos que despertaram a atenção de um grupo social composto por pesquisadores, especialmente da Universidade Federal do Rio Grande do Sul (UFRGS). Esses pesquisadores puderam contribuir, por exemplo, com uma leitura aprofundada das formas com que agricultores familiares vêm se relacionando com o ambiente frente às limitações da legislação ambiental. Com isso, evidenciaram não somente as práticas de agricultura de base ecológica que estão ocorrendo no Litoral Norte Gaúcho, como também as barreiras que limitam os processos de disseminação dessas iniciativas.

As investigações mostraram desde a necessidade de maior articulação entre conhecimentos locais e técnico-científicos, o favorecimento da criação de alternativas produtivas conservacionistas da biodiversidade nativa, do uso dos solos e da água (Martins, 2013), até a dificuldade dos agricultores familiares no acesso aos mercados (Pettenon, 2014). A gradativa aproximação entre pesquisadores e atores sociais locais já mostra resultados em iniciativas de superação de algumas adversidades que se apresentam no contexto social. Ao indicar pontos de fragilidade na realidade do campo, os pesquisadores auxiliam os atores sociais na construção de novos pontos de vista acerca das situações e, consequentemente, no aperfeiçoamento de suas intervenções no fluxo de eventos em seu entorno (Long, 2007).

Direcionados, inclusive, pelas limitações apresentadas pelas pesquisas e pelo apoio prestado por meio da mediação social, esses agricultores buscaram formas de criação de tecnologias adaptadas à conservação do ambiente e de acesso a mercados diferenciados. Assim, os associados da COOMA-
FITT, aperfeiçoando suas práticas agrícolas, conseguiram atender a demanda de dois municípios da região por meio do PAA e de 14 municípios por meio do PNAE. Algo semelhante ocorreu com a COOPVIVA que, composta atualmente por 60 associados, fornece alimentos para o PNAE em nove municípios. Segundo levantamentos realizados pelos setores administrativos de ambas as Cooperativas, suas ações conjuntas beneficiam, atualmente, mais de 45 mil pessoas via PAA e em torno de 200 mil pelo PNAE.

\section{Entrelaçando agências no traçar das escolhas tecnológicas}

As ações coletivas ou "ações organizadas" não são fenômenos espontâneos, mas construções sociais cuja existência implica também em distintos problemas que envolvem suas condições de emergência e mesmo de continuidade. Esses dispositivos coletivos, de acordo com Mormont (1996), têm como estímulo a redução ou a resolução de diferentes incertezas, no qual a eficácia está diretamente correlacionada à sua capacidade de resolução coerente dessas incertezas.

No contexto empírico estudado, os laços construídos entre distintos atores sociais se evidencia como potencial ferramenta de redução de incertezas no enfrentamento de adversidades no campo. As experiências que envolvem agricultores em processo de conversão, cujo sistema de trabalho na agricultura é transformado de um modelo convencional para um modelo de base ecológica, ilustram essa reflexão. Nesse sentido, o apoio e o incentivo de outros agricultores, extensionistas rurais e mesmo de pesquisadores têm se mostrado relevantes.

A partir de contatos, em especial com uma cooperativa de agricultores ecologistas de abran- 
gência estadual, a ECOCITRUS ${ }^{7}$, a ideia de produzir alimentos orgânicos ${ }^{8}$ e comercializá-los por intermédio da COOMAFITT ganhou um grande impulso entre os agricultores. Com isso, a opção por um conjunto de tecnologias mais adequadoao contexto socioambiental local foi sendo colocada em prática. Como já existia, desde 2010, um grupo informal que reunia em torno de seis famílias de agricultores ecologistas dos municípios de Osório, Maquiné, Terra de Areia, Três Forquilhas e Itati, a COOMAFITT decidiu apoiar e auxiliar esse grupo na busca por novos agricultores que pudessem fortalecer a iniciativa e aumentar a escala de produção. Isso fez, inclusive, com que alguns agricultores ecologistas existentes nos municípios da região se associassem à Cooperativa.

Assim, a COOMAFITT investiu em diversas atividades que tinham como objetivo principal promover a difusão de tecnologias diferenciadas daquelas atreladas ao código sociotécnico até então predominante na região. Com foco na problemática ambiental, na valorização do conhecimento local e na melhoria da renda dos agricultores familiares associados, um novo código sociotécnico foi se constituindo por meio de um misto de técnicas tradicionais, guiadas pelo saber-fazer, e tecnologias respaldadas por pesquisas científicas desenvolvidas na região.

Esse novo código sociotécnico abrange tecnologias que inter-relacionam a prática da agricultura e a conservação ambiental, tais como: a utilização do sombreamento ${ }^{9}$ nos cultivos; a rotação de espécies plantadas a fim de não se esgotar os nutrientes do solo; a aplicação de caldas para controle de pragas e doenças; preparo de compostos orgânicos para o enriquecimento da fertilidade do solo; o uso de plantas companheiras ${ }^{10}$ para otimização das áreas de cultivo e da qualidade de plantas; o preparo e o uso de biofertilizantes ${ }^{11}$; a implantação de Sistemas Agroflorestais (SAF) que combinam espécies arbóreas, frutíferas e madeireiras com cultivos agrícolas e/ou criação de animais, homeopatia, dentre outros. Além dessas técnicas, promove-se a concepção de algumas tecnologias organizacionais, as quais envolvem distintos grupos de atores sociais no preparo de dias de campo, reuniões, palestras e seminários sobre educação ambiental em escolas da região, feiras expositivas e eventos regionais.

Essas transformações sociotécnicas evidenciam que, mesmo com a convencionalização de um marco tecnológico da agricultura convencional no Litoral Norte, esses agricultores familiares visualizam a rea-

\footnotetext{
${ }^{7}$ A Cooperativa dos Citricultores Ecológicos do Vale do Caí se situa em Montenegro, região metropolitana de Porto Alegre (RS). Constituída em 1994, atualmente reúne 110 associados envolvidos com a produção de sucos de frutas, óleos essenciais e compostos para adubação, todos orgânicos (Tavares \& D’Avila, 2014).

${ }^{8}$ Alimentos de origem vegetal ou animal produzidos sem a utilização de fertilizantes sintéticos solúveis, agrotóxicos e insumos transgênicos. As práticas culturais que baseiam a produção desses alimentos são voltadas ao estabelecimento do equilíbrio ecológico do sistema agrícola (MAPA, 2015).

${ }^{9}$ Plantio intercalado de árvores, em especial as provenientes da família das leguminosas, com alguns cultivos permanentes. Essa prática tem como objetivo proteger o cultivo comercial dos raios solares e, consequentemente, melhorar a fertilidade do solo.

${ }^{10}$ As plantas companheiras são cultivadas conjuntamente por gerarem benefícios mútuos, estimulando seu desenvolvimento e melhorando a qualidade do solo. Esse "companheirismo" ocorre de diversas maneiras, como o sombreamento das espécies e a troca e liberação de nutrientes e compostos químicos, como hormônios estimulantes e repelentes.

${ }^{11} \mathrm{O}$ biofertilizante é um subproduto gerado pelo processo de biodigestão de compostos orgânicos que, em geral, possuem alta concentração de nitrogênio e baixa concentração de carbono. Ouso dos biofertilizantes auxilia na manutenção do equilíbrio nutricional das plantas, atribuindo-lhes maior defesa frente a pragas e moléstias, sem desestruturação do solo, como ocorre com o uso de fertilizantes prontamente solúveis.
} 
lidade como feita de misturas das experiências imaginadas e realizadas que justapõem e inter-relacionam diferentes materialidades e tipos de agência (Arce \& Long, 2000). Ainda que muitas dessas iniciativas já fossem realizadas pelos extensionistas rurais e agricultores familiares antes da criação da Cooperativa, muitas foram aperfeiçoadas devido à mescla de noções e experiências desses atores sociais.

Um exemplo disso é a implantação do SAF, que no passado era realizada pelos agricultores pelo método de tentativa e erro, combinando plantios de espécies distintas em um mesmo ambiente, buscando principalmente o aproveitamento de espaço físico de cultivo e sombreamento de plantas. Atualmente, com base em pesquisas, as experimentações foram aprimoradas de maneira a considerar distintos fatores, como a fertilidade do solo, crescimento de espécies cultivadas e a manutenção da fauna local.

Essa combinação de modernidade e tradição também impulsionou o desenvolvimento de tecnologias organizacionais que compõem esse código sociotécnico alternativo ao convencional. Em especial, o aprimoramento da forma de organização dos agricultores familiares na região favoreceu a transformação do grupo informal de agricultores ecologistas, num primeiro momento, em uma associação e, mais tarde, em um Organismo Participativo de Avaliação da Conformidade, denominado OPAC Litoral Norte. Trata-se de um sistema de certificação de produtos orgânicos credenciado junto ao Ministério da Agricultura, Pecuária e Abastecimento, que possui a autonomia, prevista na chamada Lei dos Orgânicos, para certificar como orgânica a produção de grupos de agricultores.

A opção dos agricultores por certificar sua produção por meio de um OPAC, ao invés da contratação de empresas de certificação por auditagem,está atrelada, em parte, aos altos preços praticados pelas empresas certificadoras (Meireles, 2003).Outro fator relevante consiste no sentimento de inconformidade com a metodologia de trabalho dessas empresas, cuja credibilidade "concedida" aos produtos de base ecológica por pessoas e estruturas alheias à comunidade, segundo os próprios agricultores, não cria um processo de autonomia da família agricultora ou da comunidade.

As experiências bem-sucedidas desse OPAC fizeram com que, ainda em seu primeiro ano de existência, algumas famílias do município de Dom Pedro de Alcântara se juntassem ao grupo. Assim, o conjunto inicial de seis membros transformou-se em um coletivo de 22 famílias, dentre as quais, atualmente, doze possuem produtos certificados e, dessas, sete estão vinculadas à Cooperativa e fornecem seus produtos certificados ao mercado institucional (Figura 2).

Ao discordar da forma de certificação de produtos orgânicos operacionalizada por certificadoras comerciais- chamadas de terceira parte por não integrarem os agricultores e trabalharem por sistema de auditagem-e optar por uma forma diferenciada de aquisição do selo de orgânico para seus produtos, esse grupo de agricultores reforça a certificação participativa. Esse tipo de certificação, por sua vez, surge como uma institucionalidade alternativa que se contrapõe ao código sociotécnico vinculado ao marco tecnológico dominante da agricultura convencional. Essa situação reitera a importância do acúmulo de agência e articulação entre grupos sociais relevantes que compartilham de mesmo marco tecnológico para que a construção de um novo código sociotécnico se efetive e possa provocar transformações significativas em um marco tecnológico convencional (Bijker, 1995; Long \& Ploeg 1994).

A análise desse conjunto de encadeamentos permite compreender que esse novo código so- 


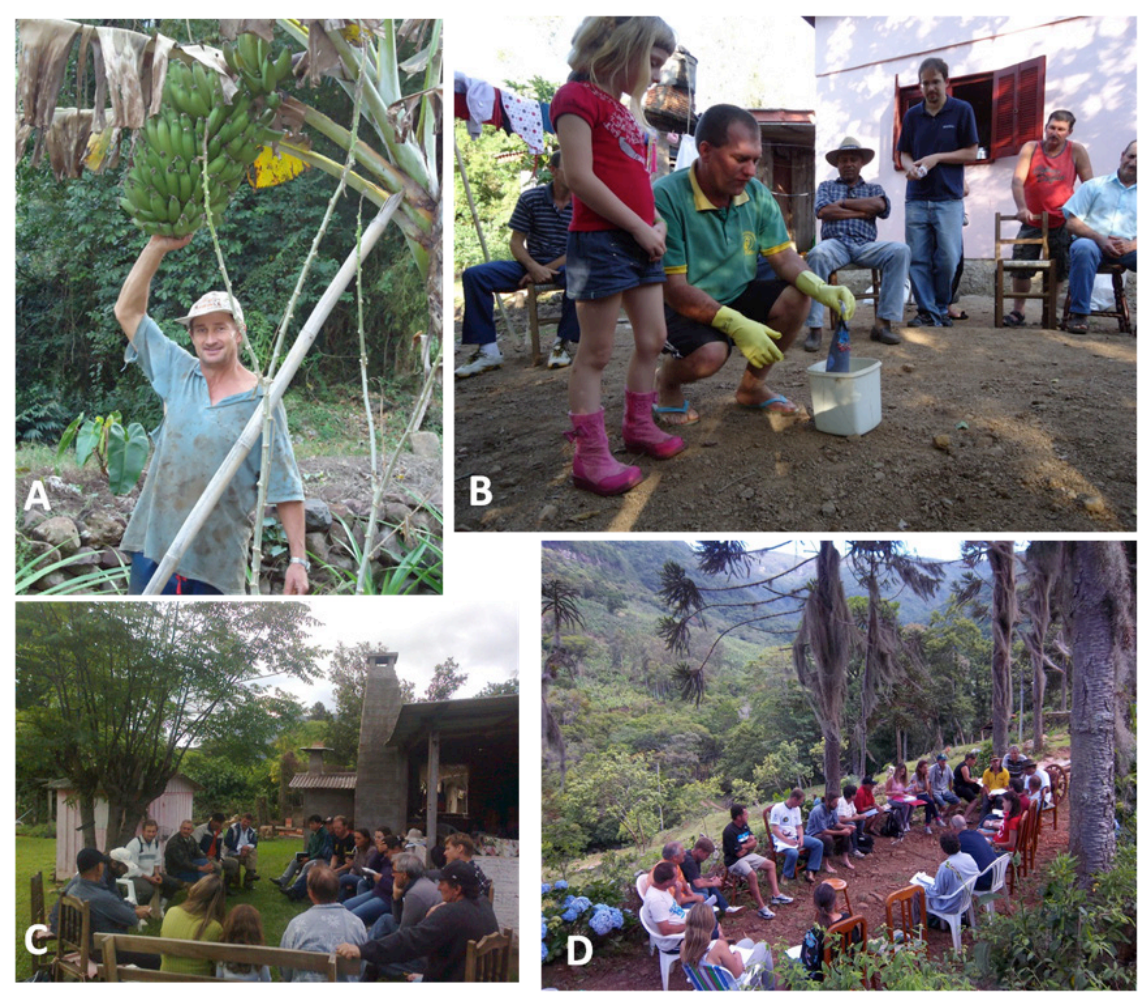

FIGURA 2 - A construção de um novo código sociotécnico. Detalhes para (A): agricultor familiar membro do OPAC Litoral Norte e associado da COOMAFITT, expondo os frutos do seu trabalho, produtos de um SAF; (B), (C) e (D): reuniões entre agricultores familiares e mediadores sociais. FONTE: Acervo pessoal elaborado durante experiência como extensionista na EMATER/ASCAR-RS.

ciotécnico constitui uma inovação relevante, que suscita modificações nas rotinas de distintos atores sociais, com potencial de promover melhorias. Isso se torna ainda mais nítido quando se verifica que a rede de relações sociais que permeia a construção desse novo código permite irradiar mudanças para além da escala local. A partir dessa rede, a COOMAFITT estabeleceu vínculos com nutricionistas e diretores de escolas que também não compactuavam com as normas do código sociotécnico preva- lecente na agricultura, em especial no que se refere à má qualidade dos alimentos até então fornecidos aos estudantes pela alimentação escolar.

Essa proximidade propiciou à organização distribuir para as escolas interessadas frutas e hortaliças produzidas de maneira mais saudável, pães elaborados à base de mandioca, abóbora e polpa de frutos da palmeira juçara ${ }^{12}$. Em 2012, as primeiras entregas de pães começaram a ser feitas nas escolas da região e, em 2014, essas entregas

\footnotetext{
${ }^{12}$ A palmeira juçara (Euterpe edulis - Arecaceae) é uma espécie original da Mata Atlântica, que ocorre desde o estado do Rio Grande do Sul até a Bahia. O beneficiamento dos frutos dessa palmeira vem sendo realizado para produzir um suco semelhante ao açaí, tradicional especiaria das regiões norte e nordeste do país.
} 
atendem, também, noventa escolas de Porto Alegre. Essa iniciativa contou com parceria da Cooperativa com a Associação de Mulheres Agricultoras para o Desenvolvimento Comunitário de Três Forquilhas (AMADECOM), um grupo de sete mulheres que trabalhava em uma agroindústria familiar construída com o apoio da ONG Centro Ecológico, com financiamento do Banco Mundial.

A partir dessa rede de relações sociais, mais famílias de agricultores familiares puderam acessar o mercado institucional e diversos estudantes de escolas públicas foram beneficiados com alimentos menos industrializados. O novo código sociotécnico, resultante do compartilhamento de perspectivas de desenvolvimento rural entre grupos sociais relevantes, constituídos por agricultores familiares e mediadores sociais, incitou outros atores sociais, a exemplo de nutricionistas e diretores de escolas, a não somente questionarem um código sociotécnico até então dominante na agricultura, como também a fortalecerem o código sociotécnico alternativo em construção.

Esses grupos sociais relevantes trabalham na construção desse novo código, tendo por referência a concepção de processos de desenvolvimento rural mais inclusivos e respeitosos com o ambiente, com destaque para a agricultura de base ecológica. As iniciativas organizacionais desenvolvidas por esses atores, que se encontram à margem do marco tecnológico vigente, vêm se mostrando como inovações, que implicam em novos modos de vida, na revisão dos padrões de consumo e em uma relação diferenciada entre agricultores e natureza, principalmente no que se refere àconcepçãodo desenvolvimento para além da esfera econômica.

Ainda que esses arranjos organizacionais estejam assumindo significativa relevância na transfiguração do espaço rural, as mudanças sociais não dependem unicamente dessas organizações. A estruturação de relações que asseguram um papel de interface entre a sociedade local e a sociedade global se faz imprescindível na melhoria da qualidade de vida dos agricultores e dos indivíduos que, de alguma forma, estão interconectados (Mercoiret, 2006). Nesse sentido, o reconhecimento público dessas iniciativas de grupos de agricultores tem se mostrado um mecanismo eficaz (Sabourin, 2005; 2009; Grisa \& Schneider, 2014; Mendonça, 2015). Esse tipo de reconhecimento favorece a arquitetura e a reformulação de instrumentos de políticas públicas, a partir da articulação dos olhares locais e de uma perspectiva global (Sabourin, 2009).

\section{5. À guisa de conclusão}

A experiência acumulada pelas diferentes organizações hoje engajadas em iniciativas de acesso ao mercado institucional é ingrediente fundamental para que as compras governamentais possam se consolidar, de fato, como uma ferramenta capaz de potencializar formas sustentáveis de produção e consumo de alimentos. Essas novas formas de mercado e de relação com o Estado, que apenas começam a vigorar, provocam novos desdobramentos, abrindo espaços para outras emergências. Esse é o caso das agroindústrias familiares, formas organizacionais autônomas de trabalho, capazes de agregar valor à produção primária. Se, por um lado, o acesso à política pública representa um avanço importante na construção de estratégias para integrar novos mercados, por outro, a iniciativa local vem demonstrando que é possível mobilizar o poder regulador e de compra do Estado na construção de novos circuitos de comercialização, com viabilidade econômica, justiça social e sustentabilidade ambiental.

O processo de modernização da agricultura, que difundiu um marco tecnológico pautado na produtividade e no lucro, desencadeou no espaço rural 
brasileiro benefícios econômicos para uma parcela diminuta de agricultores. Além dos impactos negativos sobre o ambiente, esse processo gerou dificuldades severas para a reprodução socioeconômica de numerosos agricultores familiares. Entretanto, apesar desses resultados negativos, a modernização conservadora da agricultura influenciou uma série de transformações sociotécnicas que surgiram como contraposição ao marco tecnológico dominante.

No Litoral Norte do Rio Grande do Sul, as transformações que estão sendo promovidas por distintos atores sociais compõem um novo código sociotécnico, cujo objetivo central é buscar melhorias para a condição de vida no campo, por meio de estratégias tecnológicas inovadoras na região. Tais estratégias se configuram como inovadoras, uma vez que articulam distintos atores sociais na geração de rearranjos em relações sociais e de trabalho que valorizam os conhecimentos locais e a diversidade socioambiental, ao mesmo tempo em que revitalizam vínculos de reciprocidade e confiança.

Nesse sentido, a articulação entre a Teoria da Construção Social da Tecnologia e a Perspectiva Orientada ao Ator possibilitou um modelo de análise para a compreensão dessas transformações. Dessa forma, foi possível colocar em destaque os diversos processos de aprendizagem atrelados à construção social da tecnologia e às formas de adaptação do conhecimento científico e tecnológico - já incorporados a equipamentos, insumos e formas de organização da produção ou a formas intangíveis e tácitas- não apenas a interesses de caráter técnico-econômico, mas ao conjunto de aspectos de naturezas socioeconômica e ambiental que constitui a construção da tecnologia. À luz dessa articulação teórica, demonstrou-se nesse artigo como o compartilhamento de ideias que se opõem ao marco tecnológico hegemônico de agricultura oportunizou a constituição de grupos sociais relevantes e, consequentemente, um novo projeto de desenvolvimento rural na região. Para tanto, ao conceberem as inferências da modernização da agricultura como problemáticas, em diversos aspectos, esses grupos sociais relevantes influenciaram, de diferentes maneiras, na construção de dispositivos coletivos e na sua dinâmica de evolução.

As trajetórias das duas cooperativas - COOMAFITT e COOPVIVA - evidenciam as políticas públicas de compra de alimentos como instrumento relevante para o fortalecimento de outros grupos locais, como os agricultores ecologistas e as mulheres agricultoras. Além disso, proporcionaram o engajamento de nutricionistas e diretores de escolas como atores sociais estratégicos na operacionalização do PNAE e na aquisição de alimentos menos industrializados e produzidos localmente. Esses processos motivaram os agricultores familiares a se desafiarem não somente na ampliação e na diversificação de sua produção nas unidades produtivas, como também a se unirem a outras famílias de agricultores.

O protagonismo dos atores sociais envolvidos com essas inovações está relacionado ao propósito constante de superação de dificuldades, ao rompimento das regras estabelecidas pelo marco tecnológico "modernizante" de agricultura e está inserido em processos mais amplos, que ocorrem em um nível da ação social que extrapola o espaço local. Entretanto, apesar das potencialidades desses processos na contradição à lógica hegemônica, evidenciam-se limitações no que se refere a sua abrangência. Ao serem permeadas por disputas de interesses e até mesmo por favorecimentos, determinados grupos sociais praticamente não possuem voz nessas construções. Dessa forma, entre os apontamentos que emergem desse artigo, consta a necessidade de aprofundamento das análises nesse sentido. Para tanto, sugere-se a integração de uma 
perspectiva teórica ao enquadre analítico utilizado nesse trabalho, a qual assuma as contingências da participação social frente às estruturas consolidadas de um modelo hegemônico.

\section{Referências}

Almeida, J. A construção social de uma nova agricultura. 2. ed. Porto Alegre: Editora da UFRGS, 2009.

Arce, A.; Long, N. Reconfiguring modernity and development from an anthropological perspective. In: Arce, A.; Long, N. (Org.). Anthropology, developmentand modernities: exploring discourses, counter-tendencies and violence. London: Routledge, 2000. p. 1-31.

Ação Nascente Maquiné (ANAMA)/Universidade Federal do Rio Grande do Sul (UFRGS). Faculdade de Ciências Econômicas. Programa de Pós-Graduação em Desenvolvimento Rural (PGDR). Diagnóstico socioeconômico e ambiental do município de Maquiné - RS: perspectiva para o desenvolvimento rural sustentável. Porto Alegre: UFRGS, 2000.

Ação Nascente Maquiné. Quem somos. 2015. Disponível em: <http://www.onganama.org.br/quem_somos.htm>. Acesso em: 10 jun. 2015.

Bijker, W. E. Of Bicycles, Bakelites, and Bulbs: Toward a Theory of Sociotechnical Change. Cambridge and London: The MIT Press, 1995.

Bourdieu, P. O poder simbólico. Lisboa: Difel, 1989.

Bruun, H.; Hukkinen, J. Cruzando fronteras: un diálogo entre tres formas de compreender el cambio tecnológico. In: Thomas, H.; Buch, A. (Eds.). Actos, actores y artefactos. Sociología de la tecnología. Quilmes: Universidad Nacional de Quilmes, 2008. p. 185-216.

Caporal, F. R. A extensão rural e os limites à prática dos extensionistas do serviço público. 221p. Santa Maria, Dissertação (Mestrado) - Curso de Pós-Graduação em Extensão Rural, Universidade Federal de Santa Maria, 1991.

Caporal, F. R.; Costabeber, J. A. (Orgs.). Agroecologia e extensão rural sustentável: contribuições para a promoção do desenvolvimento rural sustentável. v. 1. Brasília: MDA/ SAF/DATER/IICA, 2004. 166 p.

Carneiro, M. J. Agricultores familiares e pluriatividade: tipologias e políticas. In: Costa, L. F. C.; Bruno, R.; Moreira,
R. J. (Orgs.). Mundo rural e tempo presente. Rio de Janeiro: Mauad, 1999. p. 323-344.

Centro Ecológico. Histórico. 2015. Disponível em: <http:// www.centroecologico.org.br/historico.php $>$. Acesso em: 10 jun. 2015.

Cotrim, D. S.; Garcez, D.; Miguel, L. A. Litoral Norte do Rio Grande do Sul: sob a perspectiva de diferenciação e evolução dos sistemas agrários. 2007. Disponível em: $<$ http://www.cnpat.embrapa.br/sbsp/anais/Trab_Format PDF/51.pdf>. Acesso em: 16 maio 2013.

Cupani, A. Fazer ciência em uma época marcada pela tecnologia. Revista Internacional Interdisciplinar INTERthesis, [S.1.], 11(2), 1-14, 2014. Disponível em: <https://periodicos. ufsc.br/index.php/interthesis/article/view/18071384.2014v 11n2p1/28086>. Acesso em: 16 jan. 2015.

Fertrin, R. B. O processo de construção social da tecnologia: o caso do projeto habitacional Jardim dos Lírios. 418 p. Campinas, Dissertação (Mestrado em Política Científica e Tecnológica) - Núcleo de Pós-Graduação do Instituto de Geociências, Universidade Estadual de Campinas, UNICAMP, 2008.

FNDE - Fundo Nacional de Educação. Programa de Alimentação Escolar (PNAE): Apresentação. Disponível em: $<$ http://www.fnde.gov.br/programas/alimentacao-escolar/ alimentacao-escolar-apresentacao $>$. Acesso em: 18 out. 2011.

Geels, F. W. Understanding system innovations: a critical literature review and a conceptual synthesis. In: Elzen, B.; Geels, F. W.; Green, K. System Innovation and the Transition to Sustainability:theory, evidence and policy. Cheltenham, Northampton: Edward Elgar, 2004. p. 19-47.

Gerhardt, C. H. Agricultores familiares, mediadores sociais e meio ambiente: a construção da "problemática ambiental" em agroecossistemas. Porto Alegre, Dissertação (Mestrado) - Programa de Pós-Graduação em Desenvolvimento Rural (PGDR), Universidade Federal do Rio Grande do Sul. 2002. 
Giddens, A. The constitution of society: outline of the theory of structuration. Cambridge: Polity Press, 1984.

Godoi, C. K.; Mattos, P. L. C. L. Entrevista qualitativa: instrumento de pesquisa e evento dialógico. In: Godoi, C. K. et al. (Org.). Pesquisa qualitativa em estudos organizacionais: paradigmas, estratégias e métodos. São Paulo: Saraiva, 2006. p. 301-323.

Grisa, C.; Schneider, S. Três gerações de políticas públicas para a agricultura familiar e formas de interação entre sociedade e estado no Brasil. Revista de Economia e Sociologia Rural, 52, 125-146, 2014.

IBGE. Censo Demográfico - Brasil 2010. Rio de Janeiro. Disponível em: <www.ibge.gov.br>. Acesso em: 17 jun. 2013.

Long, N. Development sociology: actor perspectives. London and New York: Routledge, 2001. 293 p.

Long, N. Sociología del desarrollo: una perspectiva centrada en el actor. México: Centro de Investigaciones y Estudios Superiores en Antropología Social, Colegio de San Luis, 2007.

Long, N.; Ploeg, J. D. Heterogeneity, actor and structure: towards a reconstitution of the concept of structure. In: Booth, D. Rethinking social development theory, research and practice. England: Longman Scientific \& Technical, 1994. p. 62-90.

MAPA - Ministério da Agricultura, Pecuária e Abastecimento. O que são alimentos orgânicos. Brasília: MAPA, 2015. Disponível em: <http://www.agricultura.gov.br/ desenvolvimento-sustentavel/organicos/o-que-e-agricultura-organica>. Acesso em: 07 nov. 2015.

MDS - Ministério do Desenvolvimento Social e Combate à Fome. Programa de Aquisição de Alimentos. Brasília: MDS, 2015. Disponível em: <http://www.mds.gov.br/segurancaalimentar/aquisicao-e-comercializacao-da-agricultura-familiar>. Acesso em: 14 mar. 2015.

Martins, G. Agricultura familiar e seus sistemas de produção na encosta atlântica da Bacia Hidrográfica do Rio Maquiné-RS/Brasil. Porto Alegre, Dissertação (Mestrado em Desenvolvimento Rural) - Faculdade de Ciências Econômicas, Universidade Federal do Rio Grande do Sul, 2013.

Medaglia, V. R. Filosofia do meio ambiente e gestão compartilhada da biodiversidade da Mata Atlântica: debates públicos sobre a coleta de frutos da palmeira juçara no Rio Grande do Sul. Porto Alegre, Dissertação (Mestrado em Desenvolvimento Rural) - Programa de Pós-Graduação em Desenvolvimento Rural, Faculdades de Ciências Econômicas, Universidade Federal do Rio Grande do Sul, 2010.

Meireles, L. A certificação de produtos orgânicos: caminhos e descaminhos. Ipê, RS: Centro Ecológico, 2003.

Mendonça, M. A. Sistemas agroalimentares e sustentabilidade: sistemas de certificação da produção orgânica no Sul do Brasil e na Holanda. Porto Alegre, Tese (Doutorado) - Programa de Pós-Graduação em Desenvolvimento Rural, Faculdade de Ciências Econômicas da UFRGS, 2015.

Mercoiret, M.-R. Les organisations paysannes et les politiques agricoles. Afrique Contemporaine (AFD - De Boeck), 1(217), 135-157, 2006.

Mormont, M. Agriculture et environnement: pour une sociologie des dispositifs, Economie Rurale, 236, 28-36, 1996.

Nicolino. P. P. N. Resposta ao pedido de esclarecimento. Prefeitura Municipal de Várzea Grande. Estado de Mato Grosso do Sul. 2014. Disponível em: <http://www.varzeagrande.mt.gov.br/storage/Arquivos/esclarecimentosburitigranderesposta.pdf $>$. Acesso em: 31 out. 2015.

Palmeira, M. Modernização, Estado e questão agrária. Estudos Avançados, 3(7), 87-108, 1989. Disponível em: <http:// www.scielo.br/scielo.php?script=sci_arttext\&pid=S0103$-40141989000300006 \& \operatorname{lng}=\mathrm{en} \& \mathrm{nrm}=\mathrm{iso}>$. Acesso em: 10 ago. 2015.

Pettenon, L. da S. Dinâmicas do conhecimento e a emergência de novidades na agricultura de base ecológica no Litoral Norte do Rio Grande do Sul. Porto Alegre, Dissertação (Mestrado em Desenvolvimento Rural) - Faculdade de Ciências Econômicas, Universidade Federal do Rio Grande do Sul,2014.

Pinch, T; Bijker, W. The social construction of facts and artifacts: Or how the sociology of science and the sociology of technology might benefit each other. In: Bijker, W.; Hughes, T; Pinch, T. The social construction of technological systems: New directions in the sociology and history of technology. Cambridge, MA: MIT Press, 1987. p. 17-50.

Pinch, T.; Bijker, W. La construcción social de hechos y de artefactos: o acerca de cómo la sociología de la ciencia y la sociología de la tecnología pueden beneficiarse mutuamente. In: Thomas, H.; Buch, A. (Eds.). Actos, actores y 
artefactos.Sociología de la tecnología. Quilmes: Universidad Nacional de Quilmes, 2008. p. 19-62.

Ploeg, J. D. van der. La reconstitución de la localidad: tecnología y trabajo en la agricultura moderna. Prácticas ecológicas para una agricultura de calidad. In: Anais del I Congreso de la Sociedad Española de Agricultura Ecológica. Toledo, setembro de 1994. p. 423-447.

Ploeg. J. D. van der.; Bouma, J.; Rip, A.; Rijkenberg, F. H. J.; Ventura, F.; Wiskerke, J. S.C. On regimes, novelties, niches and co-production. In: Wiskerke, J. S. C.; Ploeg, J. D. van der (Eds.). Seeds of transition:essays on novelty production, niches and regimes in agriculture. Assen: Royal van Gorcum, 2004. p. 1-30.

Sabourin, E. Organizações formais e dispositivos coletivos dos agricultores no Nordeste Semiárido. In: Sabourin, E. (Org.). Associativismo, cooperativismo e economia familiar no meio rural. Brasília: UnB; Ceam; Neagri, 2006. p. 51-93. (Cadernos do Ceam, 23)

Sabourin, E. Camponeses do Brasil: entre a troca mercantil e a reciprocidade. Rio de Janeiro: Garamond, 2009.

Tavares, M. F. F.; D'Avila, T. Sustentabilidade como agregação de valor no agronegócio:ocaso Ecocitrus. ESPM central de cases. 2014. Disponível em: $<$ http://www2.espm.br/ sites/default/files/ecocitrus.pdf $>$. Acesso em: 11 jun. 2015.

Thomas, H. De las tecnologías apropiadas a las tecnologías sociales: conceptos/estrategias/diseños/acciones. Conferência apresentada na $1^{a}$ Jornada sobre Tecnologías Sociales, Programa Consejo de la Demanda de Actores Sociales (PROCODAS)-MINCyT. Buenos Aires,2009.

Thomas, H.; Fressoli, M.; Latouf, A. Introducción. In: Thomas, H.; Bunch, A. (Org.). Actos, actores y artefactos: sociología de la tecnologia. 1. ed. Bernal: Universidade Nacional de Quilmes, 2008. p. 9-17. 